\title{
EKG or ECG Monitor Device
}

National Cancer Institute

\section{Source}

National Cancer Institute. EKG or ECG Monitor Device. NCI Thesaurus. Code C50075.

A device designed to give a continuous reading of the electrical currents of the heart. 